\title{
O uso de episódios de história da matemática em uma tarefa didática visando a produção de significado
}

\author{
The use of history episodes of mathematics in a didactic task looking at the production \\ of meaning
}

\author{
Benjamim Cardoso da Silva Neto \\ benjamim.neto@ifma.edu.br \\ Fabiana Leal Nascimento \\ benjamim.neto@ifma.edu.br \\ Adelino Candido Pimenta \\ benajmim.neto@ifma.edu.br
}

\begin{abstract}
Resumo
O presente trabalho remete a uma abordagem qualitativa e por meio de uma pesquisa de campo realizada com dois alunos do $2^{\circ}$ ano do Ensino Médio, aos quais foi aplicada uma tarefa didática com uso de episódios da história da matemática para o estudo do Teorema de Tales. Objetivamos analisar a produção de significado sob o aporte do Modelo dos Campos Semânticos (MCS), adotado como referencial epistemológico na pesquisa. Construímos um episódio em relato tradicional sobre a estruturação do Teorema de Tales a partir do problema do cálculo da altura da pirâmide por Tales de Mileto no Egito Antigo. Analisamos os registros escritos dos alunos, as falas transcritas e gestos evidenciando uma leitura sobre a produção de significado matemático pelos alunos. As produções dos alunos caminharam na direção que era objetivado, ocorrendo produção de significado matemático para a tarefa submetida à aplicação. A tarefa elaborada, para os autores, é capaz de se tornar um instrumento que se incorpore às estratégias adotadas por professores de Matemática no uso da história da matemática na sala de aula possibilitando a aproximação entre aluno e professor e entre aluno e aluno, uma vez que o MCS permite e vislumbra essa aproximação entre os indivíduos.
\end{abstract}

Palavras-chave: Tarefa didática; Episódio de história da matemática; Modelo dos Campos Semânticos.

\begin{abstract}
The present work refers to a qualitative approach and through a field research carried out with two students of the 2nd year of High School, to which was applied a didactic task using episodes of the history of mathematics for the study of the Thales Theorem. We aim to analyze the production of meaning under the contribution of the Semantic Fields Model (SFM), adopted as an epistemological reference in the research. We construct an episode in traditional report on the structuring of the Tales Theorem from the problem of calculating the height of the pyramid by Tales of Miletus in Ancient Egypt. We analyzed the written records of the students, the transcribed speeches, and gestures evidencing a reading about the production of mathematical meaning by the students. The productions of the students walked in the direction that was objectified, occurring production of mathematical meaning for the task submitted to the application. The elaborated task, for the authors, is capable of becoming an instrument that is incorporated into the strategies adopted by Mathematics teachers in the use of the history of mathematics in the classroom, enabling the approximation between student and teacher and between student and student, once that SFM allows and envisions this approximation between individuals.
\end{abstract}

Key words: Didactic task; Math history episode; Semantic Fields Model..

\section{Introdução}

A presente pesquisa de campo tem uma abordagem qualitativa e foi desenvolvida com uma turma de alunos do $2^{\circ}$ ano do Ensino Médio de uma escola pública da cidade de São Raimundo das Mangabeiras - Maranhão. Constitui-se em parte de um trabalho de dissertação 
de Mestrado Profissional em Educação para Ciências e Matemática que culmina com a elaboração, aplicação e validação de um produto educacional. Têm-se como objetivo geral analisar a produção de significados matemáticos de alunos sob o aporte epistemológico do Modelo dos Campos Semânticos (MCS).

A disciplina de Matemática é taxada como complicada e difícil pelos alunos e se torna atrativa quando seu ensino é vinculado a recursos e estratégias metodológicas que visam à melhoria do processo ensino-aprendizagem. Com esta ideia e influenciados pela noção de significado e conhecimento expressos no MCS. Proporcionou-se uma aliança entre o MCS e o recurso história da matemática sob a forma de episódios.

Construiu-se um episódio em relato tradicional sobre a estruturação do Teorema de Tales a partir do problema do cálculo da altura da pirâmide e foi proposta uma tarefa aos alunos. O trabalho traz as resoluções por meio de registros escritos, gestos e falas de alunos, que na concepção dos autores produziram significados de acordo com o que é apontado no MCS. As produções dos alunos caminharam na direção que era objetivado, o que promove a validação da tarefa desenvolvida na pesquisa.

\section{Referencial teórico}

O referencial teórico adotado para o trabalho com a produção de significados difere das teorias piagetianas e também da didática francesa que possui caracterizações diferentes do modelo que adotamos (HENRIQUES, 2013). O MCS de acordo com (SILVA, 2003) nos permite identificar os significados que cada sujeito produz, no interior de uma atividade, para um determinado objeto que está sendo constituído por este sujeito.

\section{Um pouco de história}

De acordo com Eves (2004) o racionalismo impulsionou a geometria demonstrativa iniciada no século VI a. C. por Tales de Mileto. Tales, ao que se tem escrito, teria nascido em 640 a. C em Mileto na Grécia Antiga daí veio seu nome e falecido por volta de 548 a. C.. Iniciou sua vida profissional como mercador tornando-se rico e dedicou a parte final de sua vida aos estudos (EVES, 2004). Devido a sua influencia econômica e intelectual era convidado por outras civilizações para fornecer contribuições científicas e compreensões sobre o Universo.

Segundo Santos (2012) existem dúvidas quanto à origem e obras de Tales de Mileto. Mas em "relato tradicional" (ROQUE, T., 2012), o primeiro a anunciar suas descobertas foi Heródoto, em obra escrita por volta de 440 a.C. depois da morte de Tales. Para Boyer (1996) o conhecimento que se tem sobre Tales é muito pouco, mas as hipóteses sobre sua existência e descobertas são plausíveis, assim como as provocações e convites por conta da sua inteligência. Tales de Mileto, no entanto, teria sido um dos grandes matemáticos gregos e suas 
descobertas evidenciaram uma matemática mais formal, moderna.

Segundo Eves (2004) e Roque, T. (2012) o Teorema de Tales teria se fundamentado quando Tales de Mileto foi solicitado pelos escribas do faraó no Egito Antigo, a calcular a altura de uma Pirâmide ainda quando vivia na região. O episódio que não se sabe ao certo se é verdadeiro ou falso (LINTZ, 1999), marcou a construção da matemática pela relevância em se observar a interação entre a matemática e a natureza, pois Tales teria medido a altura da pirâmide por meio de sua sombra. Não sabemos de fato como ocorreu a medição da altura da pirâmide, pois não existem evidências escritas que comprovem a autoria de Tales de Mileto e devido a várias interpretações sofreu alterações dificultando a separação da história daquilo que é lenda (PEREIRA, 2005).

\section{O ensino de matemática por meio de episódios de história da matemática}

Uma visão mais profunda da história permite ao professor evoluir em seu trabalho educativo, pois dá a ele a possibilidade de ver melhor o futuro, ou seja, de enxergar antes, o que pode acontecer, as dúvidas que podem surgir. Além disso, permite que ele descubra as dificuldades do passado, comprovando os caminhos da invenção, com a percepção da ambiguidade e confusões iniciais (GROENWALD; SILVA; MORA, 2004).

Mendes (2013) considera que o uso da história como recurso pedagógico pode promover um ensino-aprendizagem que busca dar ressignificação ao conhecimento matemático produzido ao longo dos tempos, acreditando que a história da matemática é capaz de durante a ação docente causar maior motivação e aprendizagem.

A exploração de um conteúdo por meio da história da matemática pode acontecer de diversas formas seja por meio de atividades, tarefas, reprodução de instrumentos, vídeos, peças teatrais, apresentação em seminários, cartazes. Sobre este pensamento Valdés (2002) afirma que se estabelecermos um laço entre o aluno, a época e o personagem relacionado com os conceitos estudados, e se o aluno conhecer as motivações e dúvidas que tiveram os sábios da época, então, assim, ele poderá compreender como foi descoberto e justificado um problema histórico matemático.

O trabalho com episódios voltados para a história da matemática requer leitura e dedicação para quem está propondo esse recurso. Primeiramente, devemos escolher o conteúdo do qual o episódio irá tratar e a partir dele fazer um levantamento sobre sua história adotando um ponto de vista sócio cultural ou matemático para partirmos a sua aplicação. (PEREIRA; SANTIAGO; MORAIS, 2015, p.95-96).

A construção de episódios históricos de matemática inseridos em tarefas didáticas devem permitir ao aluno, i) associação com o cotidiano: os alunos devem entender que o surgimento de conceitos proveio de problemas básicos e que eles podem encontrar problemas semelhantes no dia a dia; ii) reconhecimento do período histórico e geográfico: onde eles 
fazem associação com os acontecimentos históricos da época e a região geográfica em que se deu o surgimento de algum conceito; iii) compreensão das informações: em que são capazes de entender o conteúdo que trata o episódio e as necessidades que levaram a criação dos conceitos; iv) produção de significados: promoção do conhecimento mediante suas justificações na resolução de tarefas didáticas.

\section{O modelo dos campos semânticos}

Lins ao desenvolver o MCS procurava "dar conta de caracterizar o que os alunos estavam pensando quando 'erravam', mas sem recorrer a esta ideia de erro" (LINS, 2012, p.11), levando os alunos a questionarem suas respostas, produzindo significados. "Um significado pode ser transmitido de uma pessoa a outra através do uso de algum elemento intermediário: linguagens, desenhos, gestos, disposição de objetos" (LINS, 2012, p.39).

Conforme Cézar (2014, p.33, grifos do autor) "o erro e a incerteza são elementos que surgem quando produzimos significados. Questionar essas verdades nos permite essa produção, e essa produção de significados nos conduz a construção do conhecimento." A forma como construímos conhecimento se relaciona com a forma pela qual compreendemos uma enunciação. Não existe conhecimento sem produção de significado, nem existe produção de significado sem construção de conhecimento.

Na sala de aula o processo em que se dá a produção do aluno é o que deve ser levado em conta. Os alunos pensam por serem seres humanos, a credibilidade naquilo que eles se manifestam deve ser importante e levada em consideração no processo de ensinoaprendizagem pelo professor (LINS, 2012).

\section{Metodologia}

Optamos por uma pesquisa qualitativa, pois em sua análise, a subjetividade dos autores e a adoção de interferências no diagnóstico das informações coletadas são permitidas (BOGDAN; BIKLEN, 1994). Estes autores ainda destacam que a característica fundamental de uma abordagem qualitativa é a flexibilidade que permite que as respostas dos sujeitos se baseiem em suas próprias perspectivas e não em intervenções moldadas e elaboradas.

Caracterizamos nossa pesquisa também como pesquisa de campo que se concentrou na aplicação de uma tarefa didática com o uso de episódios históricos de Matemática para alunos de uma turma do Ensino Médio. De acordo com Andrade (2007, p.127) "uma pesquisa de campo exige um planejamento geral e um plano específico para a coleta de dados, bem como um relatório escrito das várias etapas da pesquisa, incluindo os resultados obtidos". A pesquisa se dividiu necessariamente em dois momentos, a construção da tarefa, e a sua aplicação. 
Ressaltamos que neste trabalho, tarefas tem o sentido expresso por Loth (2011) quando afirma que elas: i) são produzidas para salas de aulas reais; ii) deve exigir a leitura e interpretação e textos; iii) devem possuir contexto possibilitando debates em sala de aula; iv) não devem visar o erro, mas sim, o processo.

Neste sentido elaboramos a tarefa:

Figura1: Tarefa - Tales e o problema da pirâmide

\section{Tales e o problema da altura da pirâmide}

Leia o texto que segue:

Tales de Mileto (624 a. C - 547 a. C.) é considerado um dos mais célebres gênios da Matemática da Antiguidade. A história deste grande matemático e filósofo relata que ele, ao se deparar com um problema de medição da altura de uma pirâmide, fincou um bastão verticalmente no chão, de maneira que o bastão e a pirâmide estivessem paralelos. Esperou o momento do dia em que a sombra do bastão fosse igual ao seu tamanho real, para isto, realizava constantes medidas até o momento ideal, quando enfim a altura do bastão correspondia à altura de sua sombra, nesse instante, Tales mediu o comprimento da sombra da pirâmide, adicionando à metade do comprimento da sua base, pois a soma dessas medidas, segundo Tales, correspondia à altura da pirâmide.

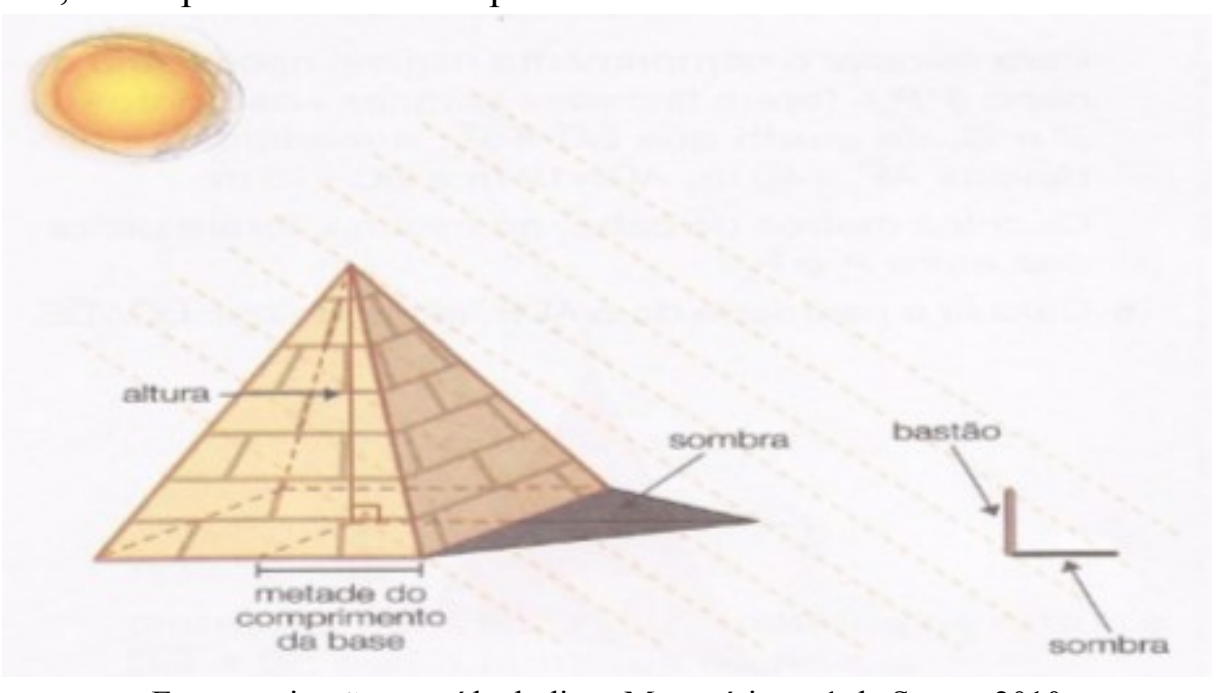

Esquematização extraída do livro Matemática v.1 de Souza, 2010

Com base nas informações apresentadas, responda:

a) Se Tales utilizando este método descrito acima, encontrou a medida da altura da pirâmide, então, a medição da altura da pirâmide aconteceu em determinado momento do dia? Justifique?

b) Como esse método, utilizado por Tales, permite que se descubra a altura da pirâmide?

c) Se este método fosse utilizado em outro momento do dia, por exemplo, o momento em que a sombra do bastão fosse a metade a da altura dele, o resultado poderia ser encontrado? De que forma? 
O objetivo principal da tarefa era despertar no aluno a busca pela curiosidade sobre o desenvolvimento da Matemática. Aplicamos a uma dupla de alunos do $2^{\circ}$ ano do Curso Técnico em Agropecuária Integrado ao Médio do Instituto Federal de Educação, Ciência e Tecnologia do Maranhão - Campus São Raimundo das Mangabeiras. Os alunos de 16 anos de idade, um do sexo masculino e outro do sexo feminino receberam os nomes de Ana Claudia e Arthur. E evidenciamos seus registros escritos conforme a aplicação da tarefa. Para as intervenções orientadas transcrevemos suas falas em itálico.

\section{Resultados}

Em nossa análise destacamos que os alunos produziram significados a partir do episódio de história da matemática presente na tarefa didática. Exibimos as três respostas dadas à Tarefa I de cada aluno, as falas transcritas dos alunos em intervenção orientada, aquela que segundo Silva (2003) busca provocar a produção de significados e nossos comentários. Ressaltamos que apenas orientamos os alunos a tentarem nos explicar suas respostas.

Os registros escritos de Ana Cláudia foram:

Figura 2: Registros escritos de Ana Cláudia

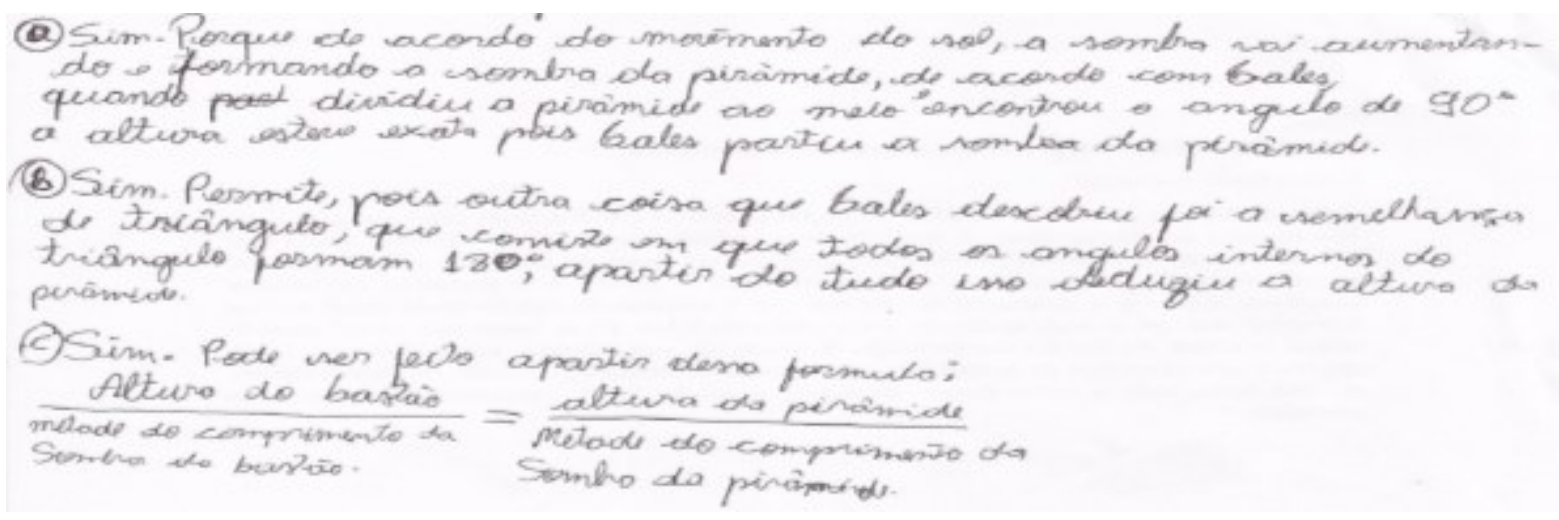

Na nossa intervenção orientada com a aluna Ana Claudia:

Ana Claudia: O Sol se movimenta e meio dia ele tá aqui em cima (apontando para o topo da pirâmide na imagem).

Pesquisador: E porque você acha que tem um ângulo de $90^{\circ}$ ? Ana Claudia: Oxe, ele forma um triângulo retângulo com a sombra.

Ana Cláudia opera a partir da posição do Sol, afirmando que sua posição varia no decorrer do dia, e com isso a sombra da pirâmide e do bastão utilizado por Tales muda de tamanho. Identificamos que a aluna utiliza argumentos que já conhece por sua vivência de matemática da rua, que aqui depreendemos uma grande relevância na resolução das tarefas.

Ana Cláudia elabora um novo esquema quando lhe é questionado sobre a possibilidade de se encontrar a altura da pirâmide quando a sombra do bastão equivaler à metade de seu tamanho original. A aluna trata as informações do texto como verdadeiras, e 
atribui que os triângulos esquematizados por Tales de Mileto são semelhantes por serem retângulos e confirma a existência dos triângulos quando afirma que possui $180^{\circ}$. Ana Claudia queria nos passar a informação de que a soma dos ângulos internos do triângulo é $180^{\circ}$. Identificamos como objeto para Ana Claudia a altura da pirâmide e produz significados na direção da semelhança de triângulos.

Os registros escritos de Arthur foram:

Figura 3: Registros escritos de Arthur

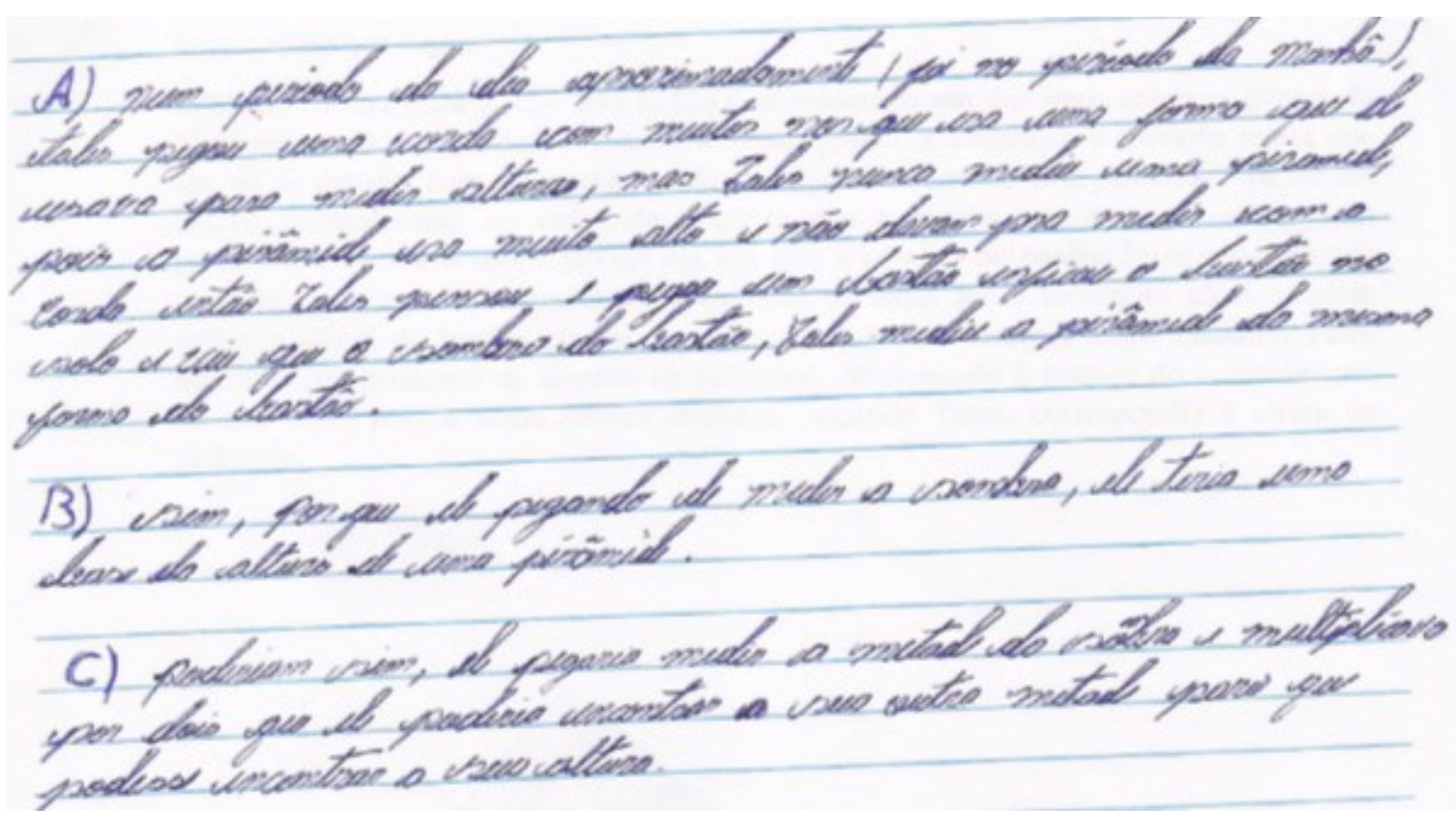

$\mathrm{Na}$ intervenção orientada:

Pesquisador: E aí Arthur como que horas você acha que Tales de Mileto teria medido a altura da pirâmide?

Arthur: Acho que foi pela manhã. Aquele povo de lá não conhecia todos os números. E ele se baseou na altura do bastão enfiado na areia.

Arthur em nossa concepção produz significados motivado pela história da matemática ao descrever métodos de medição com cordas. A direção em que Arthur emite seus argumentos não nos permitiu inicialmente perceber sua produção de significados na direção que pretendíamos. Mas logo conseguimos identificar que Arthur reproduz o pensamento de Tales, mas não opera tratando a problemática da altura da pirâmide por meio da semelhança entre dois triângulos, elabora uma comparação entre a altura do bastão de Tales e a Pirâmide. 


\section{Considerações finais}

Inserimos a História da Matemática de maneira episódica, com uma vertente do uso da história da matemática em sala de aula ainda em expansão, os episódios de história da matemática, que mesmo de maneira fantasiosa ou real, tem a capacidade de instigar os alunos a uma percepção da Matemática como um saber em construção e que partiu de problemas básicos e se estruturaram por influências de diversos personagens da matemática até chegarem aos livros didáticos.

Nossa questão primordial era saber se a história da matemática poderia contribuir para a produção de significados na perspectiva do MCS. A adoção do aporte epistemológico oferecido pelo MCS tornou-se um desafio para nós na pesquisa. Nenhum outro trabalho sinalizava este caminho utilizando a aliança entre a história da matemática e o MCS. O MCS nos permitia estabelecer uma leitura da produção dos alunos e desta forma nos dava uma visão sobre nosso trabalho enquanto professor em sala de aula.

Observamos que as práticas de muitos professores de Matemática não se enquadram em tendências e ricos recursos que podem propiciar uma vantagem positiva no processo de ensino aprendizagem. Assim, acreditamos que o nosso produto educacional venha a subsidiar a prática de professores como forma de introduzir o conteúdo de Geometria Plana não somente no $2^{\circ}$ ano do Ensino Médio, mas também em outras turmas, e também a exploração de outros métodos de se trabalhar de maneira episódica.

\section{Referências}

ANDRADE, Maria Margarida de. Introdução à metodologia do trabalho científico: elaboração de trabalhos de graduação. 8. ed. São Paulo: Atlas, 2007.

BOGDAN, Robert; BIKLEN, Sari. Investigação qualitativa em educação matemática: uma introdução à teoria e ao método. Porto, Portugal: Porto Editora, 1994.

BOYER, Carl Benjamin. História da matemática. 2. ed. trad. Elza F. Gomide. São Paulo: Edgard Blücher LTDA, 1996.

CÉZAR, Mariana dos Santos. Produção de significados matemáticos na construção dos números reais. 2014. 167f. Dissertação (Mestrado profissional em educação para ciências e matemática) Instituto Federal de Educação, Ciência e Tecnologia do Espírito Santo, Vitória, 2014.

EVES, Howard. Introdução à história da matemática. trad. Hygino H. Domingues. Campinas - SP: Editora Unicamp, 2004.

GROENWALD, Claudia Lisete Oliveira; SILVA, Carmen Kaiber; MORA, Castor David. Perspectivas em educação matemática. Acta Scientiae, Canoas, v. 6, n. 1, p.37-55, jan-jun. 2004.

HENRIQUES, Marcílio Dias. A produção de significados de estudantes do ensino fundamental para tarefas geométricas. Bolema, Rio Claro, SP, v. 27, n. 46, p. 433-450. 2013.

LINS, Romulo Campos Lins. O modelo dos campos semânticos: estabelecimentos e notas de teorizações. In: ANGELO, Claudia Laus; BARBOSA, Edson Pereira; SANTOS, João Ricardo Viola 
dos; DANTAS, Sérgio Carrazedo; OLIVEIRA, Viviane Cristina Almada de. Modelo dos campos semânticos e educação matemática: 20 anos de história. 1. ed. São Paulo: Midiograf, 2012. p. 11-30.

LINTZ, Rubens Gouveia. História da Matemática. 3. ed. Blumenau: FURB, 1999

LOTH, Maria Helena Marques. Uma investigação sobre a produção de tarefas aritméticas para o $6^{0}$ ano do Ensino Fundamental. 2011. 212 f. Dissertação (Mestrado Profissional em Educação Matemática) - Instituto de Ciências Exatas, Universidade Federal de Juiz de Fora, Juiz de Fora, 2011.

MENDES, Iran Abreu. História no Ensino da Matemática: trajetórias de uma epistemologia didática. Rematec, Natal (RN), a. 8. n. 12, p. 66-85, 2013.

PEREIRA, Ana Carolina Costa; SANTIAGO, Laura Andrade; MORAIS, Wendy Mesquita de. O uso de episódios históricos no ensino de matemática: uma sequência didática utilizando quadrinhos. In:

PEREIRA, Ana Carolina Costa; CEDRO, Wellington Lima. (Orgs.). Educação matemática: diferentes contextos, diferentes abordagens. 1. ed. Fortaleza: EdUECE, 2015. p. 89-107.

ROQUE, Tatiana. História da Matemática: uma visão crítica, desfazendo mitos e lendas. Rio de Janeiro: Zahar, 2012.

SANTOS, Márcia Nunes dos. A história da matemática como desencadeadora de atividades investigatórias sobre o teorema de tales: análise de uma experiência realizada com uma classe do 9. ${ }^{\circ}$ ano do ensino fundamental de uma escola pública de Ouro Preto (MG). 2012. 180 f. Dissertação (Mestrado Profissional em Educação Matemática) - Instituto de Ciências Extas e Biológicas, Universidade Federal de Ouro Preto, Ouro Preto (MG), 2012.

SOUZA, Joamir Roberto de. Matemática. 1. ed. 2. v. São Paulo: FTD, 2010. (Coleção novo olhar)

SILVA, Amarildo Melchíades. Sobre a dinâmica de produção de significados para a matemática . 2003. 244 f. Tese (Doutorado em Educação Matemática) - Instituto de Geociências e Ciências Exatas, Universidade Estadual Paulista, Rio Claro, 2003.

VALDÉS, Juan E. Nápoles. La História como elemento unificador em la Educación Matemática. Argentina, 2002. 